\title{
Moldando o corpo do Brasil: Jaime Cortesão, Rodrigo Octávio, a representação de Gusmão e o metajogo na região do Prata*
}

\author{
Molding the body of Brazil: Jaime Cortesão, Rodrigo Octávio, the \\ representation of Gusmão and the metagame in the Rio de la Plata region
}

\author{
Renato Amado Peixoto \\ renatoamadopeixoto@gmail.com \\ Professor associado \\ Universidade Federal do Rio Grande do Norte \\ BR 101 - Km 01, Centro de Ciências Humanas, Letras e Artes, Sala 222 - Lagoa Nova \\ 59078-970 - Natal - Rio Grande do Norte \\ Brasil
}

\section{Resumo}

A representação de Alexandre Gusmão foi sedimentada por Jaime Cortesão em 1956 no contraponto das visões baseadas nos escritos de Rodrigo Octávio, produzindo uma representação do político que se colocava contra o alinhamento aos Estados Unidos. Esta fabricação estava inserida, também, no metajogo político e historiográfico do Prata e se postava contraparte da historiografia argentina. Além disto, Cortesão estava incorporado ao projeto de autonomia e profissionalização da corporação diplomática, centrado então no IRB, visando inscrever o papel do diplomata na formação do espaço e da identidade brasileira. A criação do IRB também propiciava a autonomia do MRE em relação a um projeto de história compartilhado com o IHGB. No caso, a disseminação da produção do IRB foi dinamizada pelas prescrições deixadas pela 'Comissão Revisora dos textos de História e Geografia'. Ao articular numa mesma perspectiva todos estes metajogos historiográficos e políticos, Jaime Cortesão leva o seu analista a ter de considerar instrumentos teóricos e metodológicos que permitam explicitá-los. Entendo que isto ultrapassa certas considerações usuais em torno dos termos 'Quem e como se faz a história', levando a ter de inquirir os insumos teóricos que serviram a Michel de Certeau de modo a poder pensar as questões da representação do político e do lugar do historiador em relação à escrita da história.

Palavras-chave

Jaime Cortesão; História da historiografia; Representação.

\section{Abstract}

The representation of Alexandre Gusmão was sedimented by Jaime Cortesão in 1956 in the counterpoint of the visions based on the writings of Rodrigo Octávio and, with this, it produced a representation of the politician which stood against the Brazilian alignment with the United States. This fabrication was also inserted in the political and historiographical metagame of the Rio de la Plata region, and it was placed against part of the Argentine historiography. In addition, Cortesão was incorporated into the project of autonomy and professionalization of the diplomatic corporation, centered in the IRB, aiming at inscribing the role of diplomat in the formation of Brazilian space and identity. The creation of the IRB also facilitated the autonomy of the MRE in relation to a shared historical project with the IHGB. In this case, the dissemination of the production of the IRB was stimulated by the prescriptions left by the 'Comissão Revisora dos textos de História e Geografia'. By articulating all these historiographical and political metagames in the same perspective, Jaime Cortesão leads his analyst to consider theoretical and methodological tools that allow his analysis. I understand that this goes beyond certain usual considerations around the terms 'Who and how history is made', leading to having to inquire about the theoretical inputs that served Michel de Certeau, so that we could think about the issues of representation and the place Of the historian in relation to the writing of history.

\section{Keywords}

Jaime Cortesão; History of Historiography; Representation.

Recebido em: 22/10/2016

Aprovado em: 7/12/2016

\footnotetext{
${ }^{*}$ A primeira versão deste texto foi apresentada com o título de "A gênese da formação territorial do Brasil e os convênios para a revisão dos textos de ensino de História e Geografia com a Argentina e o Uruguai" na Jornadas 2015 da Universidad de La República Uruguay, realizada em Montevidéu entre 7 e 9 de outubro de 2015, com o apoio financeiro da Ufrninternational - Secretaria de Relações Internacionais \& Interinstitucionais da Universidade Federal do Rio Grande do Norte (UFRN).
} 
"O Brasil para os brasileiros" - segundo Jaime Cortesão - foi o lema que empolgou Alexandre de Gusmão na feitura do Tratado de Madri (CORTESÃO 1956, p. 380). Esta interpretação, ajuizada ao final do segundo tomo da Introdução da coleção Alexandre de Gusmão e o Tratado de Madri, apontava claramente o diálogo, no qual o autor lusitano se colocava, e a posição por ele defendida no metajogo historiográfico e político brasileiro. ${ }^{1}$

Cortesão se postava firmemente em contrariedade à corrente historiográfica, consolidada na década de 1930, pelas exposições e escritos de Rodrigo Octávio no Instituto Histórico e Geográfico Brasileiro (IHGB), corrente essa que fora explicitamente endossada pelo Segundo Congresso de História Nacional, em 1931. Rodrigo Octávio destacava Alexandre de Gusmão como o precursor do pan-americanismo e como o inspirador da política de aproximação em relação ao Uruguai e à Argentina, iniciada pelo Governo Washington Luís em 1927.

Contudo, há que se salientar que Cortesão não divergia apenas do arrazoado historiográfico de Rodrigo Octávio, mas também se opunha às leituras desse conteúdo feitas pelos defensores do alinhamento com os Estados Unidos no período da Guerra Fria. A expressão "O Brasil para os brasileiros", por exemplo, estava sendo contraposta à sua congênere "A América para os Americanos", empregada em 1940 por Rodrigo Octávio para se referir ao legado de Gusmão, o qual vinha sendo equiparado por ele à expressão monroísta do pensamento de Elihu Root (OCTÁVIO 1941, p. 32), secretário da guerra no governo William McKinley e secretário de estado sob Theodore Roosevelt (PEIXOTO 2011a).

Em 1940, Rodrigo Octávio havia juntado vários argumentos distribuídos em seus textos das décadas de 20 e 30 para produzir o artigo "Alexandre de Gusmão e o Monroísmo", publicado na Revista do IHGB de 1941, em boa parte para endossar as premissas de atuação da Comissão Brasileira Revisora dos Textos de História e Geografia, que havia sido liderada intelectualmente por Pedro Calmon em 1936.

Esta Comissão era resultado exatamente da política de aproximação com o Uruguai e a Argentina aplicada pelo governo Getúlio Vargas, durante a década de 1930, e que incluía o congraçamento cultural e a promoção de acordos que visavam eliminar os contenciosos, inclusive, removendo dos textos didáticos de história e geografia as passagens e conteúdos que atentassem contra as relações entre aqueles países (PEIXOTO 2015).

Cabe apontar que o artigo de Rodrigo Octávio havia sido determinante para o engajamento historiográfico de Jaime Cortesão, na medida em que propiciara a suíte de reportagens sobre Alexandre de Gusmão, dirigida por Cassiano Ricardo para o jornal $A$ Manhã, e a discussão historiográfica em que se Cortesão se integrou (PEIXOTO 2015, p. 56-57).

\footnotetext{
${ }^{1}$ Penso o termo "metajogo" por meio de uma ideia alargada de contexto - o conceito derridiano de "cena" - aplicada ao campo historiográfico com a preocupação de pensá-los enquanto jogo do mundo e jogo no mundo - o confluxo entre acaso, oportunidade, posição e interesse - visando com isso compreender os poderes envolvidos nesses jogos e sua relação com uma analítica da historicidade. Por conta disto, busco adaptar a teoria dos metajogos e do comportamento político esboçada por Nigel Howard (HOWARD 1971) para engendrar um exame simultâneo das interações continuadas entre o político e o historiográfico.
} 
Jaime Cortesão se colocava também contra a visão explicitada em 1943 por Pedro Calmon em sua coleção História do Brasil, terminada de publicar justo em 1955 - um ano antes do seu texto -, apontado que ele empregava o argumento de que a separação dos destinos da América em relação à Europa já havia se dado desde 1750 por meio da "influência realista e profética de Gusmão" (CORTESÃO 1956, p. 379).

Contudo, há que se salientar que os defensores do alinhamento à política externa dos Estados Unidos não se baseavam apenas nos argumentos de Rodrigo Octávio ou de Pedro Calmon, mas descortinavam a naturalidade e anterioridade desse posicionamento, porquanto retroagiria ao início do século, se enraizando na política de aproximação deslanchada pelo Barão do Rio Branco. Esta teria como objetivo impedir que a política externa republicana não sofresse da solução de continuidade com a da monarquia, cujas origens datavam do reconhecimento de nossa independência pelos estadunidenses que, em última análise, aninhavam-se no legado pan-americanista de Alexandre de Gusmão (PEIXOTO 2011a; 2015).

Essa ideia fora ativada por Álvaro Lins em Rio-Branco, biografia escrita e publicada em 1945 sob o patrocínio do Ministério das Relações Exteriores (MRE), para marcar a comemoração do centenário natalício do Barão. Lins alicerçava a ideia da "solução de continuidade" na interpretação de que a aproximação com os Estados Unidos fora esposada, nesses liames, pelo próprio Rio Branco no texto "O Brasil, os Estados Unidos e o Monroísmo", escrito sob o pseudônimo de J. Penn para o Jornal do Commercio, em 1906.

Em boa medida, a ativação dessa ideia também possibilitou a Álvaro Lins resedimentar outra figura do Barão do Rio Branco frente à historiografia de sua época, retrabalhando a sua atuação no comando do MRE para fazer com que esta fosse apresentada a partir de predicados verdadeiramente excepcionais. Nesse exercício, Álvaro Lins procurou equiparar o Barão do Rio Branco a Alexandre de Gusmão, juntando, ao primeiro, os predicados empregados para distinguir o segundo - a clarividência e a genialidade -, mas também rearticulando o tópos já consolidado em torno da figura de Gusmão: a continuidade dos esforços diplomáticos. Nesse intuito, Álvaro Lins optou também por juntar os esforços do Barão àqueles que haviam sido desenvolvidos por seu pai, o Visconde do Rio Branco, quando ele estava à frente da diplomacia brasileira no século XIX.

Em benefício de nosso raciocínio, entendo ser necessário circunstanciar que o texto "O Brasil, os Estados Unidos e o Monroísmo", em minha interpretação, foi escrito em apoio à mensagem do presidente Rodrigues Alves dirigida ao Parlamento em 3 de maio de 1906 e visava responder às críticas que se faziam, então, à visita de Elihu Root ao Brasil. Tais críticas tinham como argumento central o antagonismo da política externa estadunidense em relação à Monarquia e, note-se que a visita de Root se faria em seguida aos acontecidos no "Caso Panther", 2 compreendido, à época, como o exemplo

\footnotetext{
${ }^{2} \mathrm{O}$ confronto diplomático entre o Brasil e a Alemanha por causa do suposto rapto de um residente alemão em
} 
da grave ameaça que o imperialismo apresentava à soberania do país (PEIXOTO 2011a, p. 50-52).

Dessa forma, penso que a reinterpretação de Lins foi tornada operante porque o sentido atribuído ao texto "O Brasil, os Estados Unidos e o Monroísmo" se articulava não apenas com o exame da atuação de Rio Branco empreendido por Álvaro Lins, mas também com a resposta estadunidense aos acontecidos no "Caso Panther". Por conseguinte, a ideia da solução de continuidade podia ser tomada como o alicerce da defesa do alinhamento automático com os Estados Unidos, na medida em que o modus vivendi do século XIX era desvelado como o modus ponens do século XX: a potência global, os Estados Unidos, reconheceria o Brasil como potência regional. Esse engenho foi representado no livro de Álvaro Lins, enquanto uma "moldura nova e brilhante para dar relevo a um quadro antigo", que depois é transformada, durante a Ditadura Militar, numa "aliança não escrita" (PEIXOTO 2011a, p. 52-57).

Observe-se que a entrada de Jaime Cortesão no diálogo intelectual do MRE se deu apenas em 1943 e a partir da série de palestras Como se esboçou o retrato do Brasil, quando, diferentemente de Álvaro Lins, empregou-se a imagem do modelo e do retrato para se referir a um sentido da formação territorial que juntava Portugal ao Brasil e poderia ser verificado por meio dos mapas, apresentados como documentos da ocupação e penetração espacial, trazidos à história pela cartografia, de resto, um argumento que seria replicado em todos os cursos ministrados por Cortesão no Instituto Rio Branco - IRB (PEIXOTO 2015, p. 56-57).

O fato é que Jaime Cortesão, por sua vez, resedimentaria a figura de Alexandre Gusmão, em 1956, como representação do político, na medida em que seria contraposta à ideia do alinhamento automático com os Estados Unidos. Esta virada era articulada por Cortesão a partir do argumento de que, em vez do pan-americanismo, o protagonismo de Gusmão aceitava e favorecia a corrente histórica que apresentava a inevitabilidade do separatismo do Brasil e, por conta disso, Gusmão preparou o seu advento "nas dobras do Tratado de 1750", "moldando o corpo do Brasil" (CORTESÃO 1956, p. 380).

Nessa explicação, o protonacionalista Gusmão, homem-forte do estado português, secreta e intencionalmente, havia transformado o futuro por meio dos instrumentos disponibilizados pelo seu presente. Assim, havia deformando propositalmente o Mapa das Cortes. Iludindo seus congêneres ao lançar mão de ilações históricas falseadas, teria conduzido ao engano igualmente a portugueses e a espanhóis. Em suma: tinha "moldando o corpo do Brasil" para proporcionar "o Brasil para os brasileiros" (CORTESÃO 1956, p. 380).

Ao articular numa mesma perspectiva o metajogo historiográfico e político, Jaime Cortesão leva o seu analista a ter de considerar instrumentos teóricos e

Santa Catarina, em 1905, foi nomeado de "Caso Panther" em virtude do envolvimento dos tripulantes de um barco germânico, a canhoneira Panther, que já havia se envolvido anteriormente em ataques à Venezuela e ao Haiti. O episódio levou à mobilização geral da Marinha de Guerra brasileira e ao envolvimento dos Estados Unidos em favor do Brasil, resultando em profundas impressões na cultura política brasileira, especialmente no que tange ao imperialismo e à xenofobia, bem como na formulação da política externa. 
metodológicos que permitam explicitá-los. Entendo que isso ultrapassa certas considerações usuais em torno dos termos "Quem e como se faz a história", levando a ter mesmo de inquirir os insumos que serviram a Michel de Certeau para pensar as questões da representação do político e do lugar do historiador em relação à escrita da história.

Penso que juntando no mesmo argumento historiográfico o acaso ao determinismo, e a causalidade à oportunidade, Jaime Cortesão trabalhava num posicionamento sensível àqueles brasileiros de seu tempo, quando a Geografia se somava à História. Ele não apontava apenas o tempo enquanto condição meta-geográfica e como base analítica nas possibilidades geo-políticas, mas considerava também o espaço enquanto condição meta-histórica, trabalhando as implicações geo-políticas, posições passíveis mesmo de serem resgatadas para trabalharmos as questões da representação e do lugar do historiador.

No primeiro caso, ao constituir o argumento historiográfico pelo investimento numa explicação do protonacionalismo de Gusmão, "moldando o corpo do Brasil", Jaime Cortesão não apenas se colocava na luta de representações do campo político das décadas de 1940 e 1950, mas também na luta do campo historiográfico, pois estava reativando a representação de Gusmão "enformando" a Nação em seu território, esboçada há mais de cem anos pelo Visconde de São Leopoldo no seio do MRE, e que provocou a criação do IHGB (PEIXOTO 2015; 2011b).

No segundo caso, ao deslocar o problema da identidade e da nação brasileira do pan-americanismo para reconduzi-las a uma intelecção centrada em Portugal e, naquilo que idealizava como o papel dessa nação na civilização universal, Cortesão produzia uma explicação empreendida nas transições e nos arranjos complexos do metajogo político e historiográfico. Compreendendo que a produção historiográfica do Brasil se articulava à da região platina, a esta sobrepôs a ligação à produção lusitana, discernindo e amplificando o campo da produção historiográfica nucleado no IRB, Cortesão desobrigou os interesses da corporação diplomática dos arranjos operados noutras instituições e possibilitando, assim, a constituição daquilo que viria a ser chamado por José Honório Rodrigues de Política Externa Independente.

Ambos os casos nos possibilitam inquirir não apenas a ideia do papel do historiador em relação à escrita da História, mas a própria ideia de seus lugares. Visando isso, começaremos pela exegese do esforço que abrigou o exercício historiográfico de Jaime Cortesão no IRB; depois, analisaremos esse exercício em relação ao diálogo com a produção da região historiográfica platina, para, finalmente, inquirir a reativação da representação de Gusmão em 1956.

\section{A coleção Alexandre de Gusmão e a consolidação do IRB}

Em 1950, na comemoração do bicentenário do Tratado de Madri, o MRE começaria a publicar a coleção Alexandre de Gusmão e o Tratado de Madri, composta por nove volumes, sob a organização e a direção de pesquisa de Jaime Cortesão. Naquele ano sairiam, fora da ordem de organização, dois volumes: Obras várias de Alexandre de Gusmão e Documentos Biográficos 
- respectivamente os Tomos I e II de sua Parte II; no ano seguinte seriam publicados os dois tomos de sua Parte III - os Antecedentes do Tratado.

Somente em 1952, às vésperas de se completarem os duzentos anos do falecimento daquele que fora chamado de "avô dos diplomatas brasileiros" (JORGE 1916), é que começaria a ser publicada a contribuição autoral de Jaime Cortesão, o Tomo I da Parte I da Coleção, nomeado de Introdução (16951735). Entretanto, o seu Tomo II - Introdução (1735-1753) -, somente sairia da Imprensa Oficial em 1956. Os volumes restantes da Coleção, a Parte IV (Negociações, em dois tomos) e Execução do Tratado (Parte V) seriam publicados até o ano de 1960.

Entretanto, a organização e publicação da Coleção não era um esforço isolado do IRB, mas fazia parte do ambicioso Plano de Pesquisa no Brasil articulado em abril de 1947 pelo diretor do IRB, Hélio Lobo. O Plano previa a outorga de bolsas de pesquisa anuais, bônus na entrega dos resultados em forma de livro, planejamento para impressão em editoras comerciais, pesquisa no exterior a ser realizada por funcionários do MRE e convênios com as Seções de História do Brasil das principais faculdades de filosofia.

O Plano de Hélio Lobo juntava nove projetos de pesquisa sob a direção de pesquisadores já distinguidos em esforços correlatos aos objetos de estudo dos projetos, caso de Jaime Cortesão, José Honório Rodrigues, Gilberto Freire, Artur César Ferreira Reis, Virgílio Correia Filho, Bruno de Almeida Magalhães e Octávio Tarquínio de Souza.

No entanto, apenas dois projetos - De Tordesilhas a Saragoça, 1494-1529 e Tratado de Madrid, 1750 - ficaram a cargo de um único pesquisador, Jaime Cortesão. O segundo deles seria exatamente o que daria origem à coleção Alexandre de Gusmão e o Tratado de Madri, e já era diferenciado dos demais projetos do Plano na medida em que Ihe eram destinados recursos suficientes para uma execução mais longa e onerosa, e se havia previsto a publicação dos seus resultados pela Imprensa Nacional. Isto acontecia porque o projeto Tratado de Madrid, 1750 estava destinado pelo próprio IRB à condição de sua contribuição para as comemorações do bicentenário do Tratado (MRE 1947b).

No sentido de melhor se colocar o argumento de que a inserção de Jaime Cortesão no esforço do MRE deve ser pensada no metajogo político e historiográfico, é necessário observar que: as tarefas delegadas a Jaime Cortesão antes de 1947 não tinham a ver com a pesquisa; que o Plano de Pesquisas de Hélio Lobo discrepava completamente dos objetivos atribuídos ao IRB; que o projeto Tratado de Madrid, 1750 surgira a reboque dos interesses de Cortesão; que seus interesses se articulavam com os objetivos da corporação diplomática; e que outro esforço de Cortesão, no âmbito da Biblioteca Nacional (BN), operava neste metajogo.

No que tange ao contrato acordado entre Jaime Cortesão e o MRE ainda no início de 1944, as tarefas às quais deveria se dedicar estavam distribuídas entre várias atividades e apenas umas delas, a organização do Atlas Histórico do Brasil, tangenciava a pesquisa. As demais diziam respeito às melhorias no funcionamento da Mapoteca do Itamaraty e à recapacitação do funcionalismo do Ministério, como a catalogação de arquivos, a consultoria e a docência (MRE 1946a). 
Em relação aos objetivos do IRB, embora a pesquisa estivesse prevista entre as finalidades do Instituto pelo decreto-lei que regulava sua criação, sua direção não a considerava nem mesmo uma atividade secundária em 1946 - o caso dos seus cursos de extensão que, embora tivessem sido restritos à mínima atividade possível, estavam incluídos no planejamento do Instituto. Esse posicionamento derivava do entendimento de que todos os esforços do IRB deveriam estar focados no aperfeiçoamento dos servidores do MRE e na preparação de candidatos com a carreira diplomática e consular (MRE 1946b).

É importante considerar, no sentido de pensar a articulação dos interesses de Cortesão com os objetivos da corporação diplomática, que pelo menos dois dos memorandos expedidos pela direção do IRB, no ano de 1946, apontavam as enormes dificuldades enfrentadas para apenas se conseguir manter as novas regras de ingresso na carreira diplomática, provavelmente determinando que o foco do Instituto fosse mantido nos cursos de aperfeiçoamento e admissão. Pela leitura desses memorandos, fica claro que a direção do Instituto sofria grandes pressões para que se permitisse o ingresso de candidatos reprovados no exame vestibular do IRB, e que isto apenas repetia a velha prática de apadrinhamento, considerada responsável pelos desníveis na formação e no desempenho dos diplomatas (MRE 1946c; 1946d).

O interessante é que, paralelamente às reclamações contra o "pistolão" e os "protetores ou padrinhos", se expressasse também a ideia de um novo papel a ser desempenhado na sociedade pelo IRB, e por uma Fundação Rio Branco ainda a ser criada (MRE, 1946c; 1946d). Aqui se detecta a formulação de que um campo de atuação dos diplomatas deveria se constituir no mesmo modelo em que então se organizavam as carreiras acadêmicas no Brasil, para o qual se pleiteava, inclusive, a formação de uma reserva de atuação fora das flutuações dos interesses políticos e, para isto, se salientava que o IRB deveria levar adiante, a despeito de suas limitações orçamentárias (MRE, 1946b), "um plano universitário capaz de garantir o nível cultural indispensável ao exercício da função diplomática" e almejar o "incremento da pesquisa histórica", considerando o "aprofundamento da consciência internacional de nosso povo" (MRE, 1946c). Por conseguinte, mais do que uma simples escola de diplomacia, o IRB era pensado no concerto das atribulações passadas e presentes da corporação diplomática, e sincronizado com as ambições de seus integrantes como um "verdadeiro centro de irradiação cultural e de pesquisas históricas, destinado a desempenhar um papel relevante na história da cultura e da política internacional do Brasil" (MRE 1946c).

Penso que a influência de Jaime Cortesão é inegável, não apenas porque nessas formulações transparecem certos conteúdos de seus cursos História da Cartografia Política do Brasil e História da Formação Territorial do Brasil, mas por causa desses conteúdos já refletirem suas atividades de pesquisa. É importante considerar que essas atividades somavam-se à sua atuação de liderança enquanto docente e que ambas se desdobravam em apoio à consolidação e à expansão das atividades do IRB, acrescendo-se à visão que dele se fazia na corporação. Além disso, é necessário salientar que a frequência e a aprovação nos cursos 
ministrados por Jaime Cortesão no Instituto eram, então, determinantes para a progressão funcional dos diplomatas de carreira (PEIXOTO 2014, p. 201-202).

No endosso deste argumento da aliança entre as atuações de Cortesão e da Corporação, dois registros comprovam que o projeto Tratado de Madrid, 1750 derivava diretamente da atividade autônoma de pesquisa de Jaime Cortesão, voltada então para os seus cursos e, indiretamente, ao debate com Rodrigo Octávio.

Em 1952, no prefácio ao Tomo I da Introdução da Coleção, Jaime Cortesão aponta que desde 1944, quando começara a lecionar o curso História da Cartografia do Brasil, havia cuidado "de fazer buscar e copiar a correspondência sobre as negociações do Tratado, que se encontrava dispersa em arquivos de Lisboa", processo que demorou dois anos. Segundo Cortesão, este resultado foi convertido para o conteúdo de suas aulas, cujo sucesso chamou a atenção da direção do IRB, determinando que a organização da Coleção fosse confiada a ele em abril de 1947, por conta de o Instituto se posicionar frente às comemorações do bicentenário do Tratado em 1950 e do falecimento de Gusmão em 1953 (CORTESÃO 1952, p. 5).

Esse relato fica, em sua maior parte, corroborado pelo memorando de João Guimarães Rosa, à época Chefe da Secretaria do IRB, que nos traz outros elementos, efetivamente confirmando que a organização da Coleção já havia sido confiada a Cortesão, antes mesmo da elaboração do Plano de Hélio Lobo, e que Cortesão já havia acertado verbalmente a venda de toda a documentação acerca do Tratado e de Gusmão para o IRB, pelo mesmo valor de sua aquisição em Portugal. O problema é que tanto o volume (cerca de 1.200 folhas de papel almaço), quanto o valor (correspondente a dois meses do salário de Cortesão no IRB), bem como a indicação de que o acerto verbal teria ocorrido provavelmente em 1946, faz supor a cumplicidade de Hildebrando Accioly, diretor do IRB, no engajamento de Cortesão na pesquisa, até porque Accioly estava presente na reunião de abril de 1947 embora já não fizesse mais parte do IRB (MRE, 1947a).

\section{A coleção De Angelis e o metajogo da região historiográfica do Prata}

Seguindo o argumento de que a inserção de Jaime Cortesão no esforço do MRE deve ser pensada no metajogo político e historiográfico, se deve levar em conta que paralelamente à coleção Alexandre de Gusmão e o Tratado de Madri, Jaime Cortesão também estava à frente da organização e publicação dos Manuscritos da Coleção De Angelis para a BN, e vários registros apontam o entrelaçamento das duas atividades.

A Coleção da BN era composta por sete volumes e os dois primeiros foram publicados na ordem de organização da Coleção em 1951 e 1952 - Jesuítas e Bandeirantes no Guairá (1594-1640) e Jesuítas e Bandeirantes no Itatim (15961760) - mas os que Ihe seguiram foram os volumes $\mathrm{V}$ e VI, publicados fora da ordem nos anos de 1954 e 1955, sendo que os volumes III e IV sairiam somente em 1969 e 1970, junto com o volume VII.

O leitor deve notar que os volumes da coleção De Angelis publicados nos anos de 1954 e 1955, Tratado de Madri - Antecedentes - Colônia do Sacramento 
(1669-1749) e Antecedentes do Tratado de Madri - Jesuítas e Bandeirantes no Paraguai (1703-1751), se relacionavam diretamente com os dois textos autorais de Jaime Cortesão sobre Gusmão (também publicados fora da ordem) em 1952 e 1956, e endossavam seus argumentos pela exposição da documentação dos antecedentes do Tratado de Madri.

Voltando com o argumento de que a atividade autônoma de pesquisa realizada por Cortesão antecipou os movimentos no IRB e de que seus cursos no Instituto consolidaram a aliança de sua atuação com a corporação diplomática, noto que esses rastros podem ser descortinados na própria Introdução da coleção De Angelis. Nesta, Jaime Cortesão aponta que utilizara largamente os documentos dessa coleção para a elaboração tanto do curso História da Cartografia do Brasil quanto de História da Formação Territorial do Brasil, realizados justamente em 1945 e 1946. Além disso, Cortesão reconhece que fora convidado para organizar tal coleção pelo ouvinte de um de seus cursos, Rubens Borba de Morais, então diretor da BN, após ele ter assistido sua exposição sobre os conflitos entre as bandeiras paulistas e os jesuítas espanhóis no Paraguai.

Na coleção De Angelis, como já acontecera na coleção Alexandre de Gusmão, se demonstra como a atividade de pesquisa de Cortesão havia desencadeado todo um processo e como a atividade docente tinha servido, enquanto instrumento transformador de sua carreira no Brasil, especialmente em relação à sua aliança com a corporação diplomática.

No caso da coleção De Angelis, embora não esteja apontado à qual curso o diretor da BN havia assistido, podemos inferir por meio do exame dos conteúdos de ambos os cursos, que se tratava de História da Formação Territorial do Brasil e como esta coleção fazia parte do Curso de Aperfeiçoamento de Diplomatas, por conseguinte, fechado a ouvintes externos. Assim, poderíamos supor que os cursos do Instituto ou, pelo menos o de Cortesão, possuíam um valor estratégico para o IRB, na medida em que funcionavam na ligação e na exposição dos valores da corporação diplomática junto aos demais integrantes do Estado.

Além disso, deve-se fazer notar que José Honório Rodrigues passou a fazer parte do corpo docente do IRB desde 1947 quando Ihe fora designada a disciplina de História do Brasil - a ser lecionada na primeira turma do Curso de Preparação à Carreira de Diplomata (MRE 1947a) -, e que ele conviveria com Cortesão tanto na Divisão de Obras Raras da BN quanto no IRB, onde formariam juntos os núcleos duros do ensino de história e da pesquisa histórica.

Sabemos também que desde agosto de 1946, bem antes, portanto do anúncio do Plano de Pesquisa no Brasil pelo IRB e do início oficial das atividades de pesquisa de Cortesão para o Instituto, uma funcionária do $M R E$, a pesquisadora de história Astréa Dutra dos Santos, já trabalhava em dias alternados da semana no IRB e na BN, caracterizando a interação das atividades de Cortesão e destas com as do IRB (MRE 1947c). Além disso, sabemos que Hélio Lobo passara a fazer parte do corpo docente do IRB ainda em 1946, ministrando a disciplina História Diplomática, para fundar, junto com Jaime Cortesão, o primeiro curso de aperfeiçoamento de diplomatas do MRE (MRE, 1946a). 
Dessa forma, entendo que as atividades de Cortesão à frente da organização e publicação dos Manuscritos da Coleção De Angelis e da coleção Alexandre de Gusmão e o Tratado de Madri, 1750 acabaram somadas ao esforço de transformação da corporação diplomática iniciado em meados da década de 1940, ou seja, o de incluir não apenas a fundação do IRB, mas a sua constituição como um centro de pesquisa e de ensino acadêmico. Por força da reforma administrativa, o IRB acabaria adensado pela tarefa de formar os ingressantes na carreira e de reciclar os seus membros intermediários (PEIXOTO 2014, p. 201-202).

Se retornarmos ao exame do primeiro volume da coleção De Angelis, observaremos ainda que a "Explicação" de José Honório Rodrigues, diretor da Divisão de obras raras e publicações da BN, postada à guisa de prefácio, aponta não apenas as origens, mas também a importância atribuída pelo MRE à documentação, e ele frisava que isto determinara mesmo a sua aquisição pelo Ministério em 1853.

Esse teor da Explicação de José Honório Rodrigues foi ratificado pela Introdução escrita por Jaime Cortesão, onde se salientava o interesse da Coleção para as discussões de limites do Brasil. Contudo, salta aos olhos que o apontamento não possuía apenas um mero interesse histórico, mas colocava a relevância da Coleção para discussões historiográficas atualizadas, sobretudo se repararmos na crítica ácida de Cortesão à atuação política de Pedro de Angelis e à radical desqualificação de sua posição enquanto historiador (CORTESÃO 1951, p. 51-53).

Penso que não fora por acaso que Cortesão destrinchara a sua Introdução em seis partes, das quais as três primeiras (Pedro de Angelis ao serviço da Argentina; De Angelis e o cavaleiro de Wallenstein; e Pedro de Angelis ao serviço do Brasil) cuidavam exatamente da atuação política e historiográfica de Pedro de Angelis. Por essas, Cortesão buscaria mostrar que Pedro de Angelis não era movido por nenhum patriotismo, mas agira sempre a soldo de algum interesse e, por conta disso se movera a favor, não apenas da Argentina, mas também do Brasil e do Paraguai. Aliás, isto fica já ajuizado ao começo da sua Introdução:

Entre o começo e o término da existência, De Angelis atravessou altos e baixos duma carreira, por vezes brilhante, mas sempre inquieta, contraditória e descontínua. Havendo se imiscuído com zelo indiscreto e mercenário às lutas políticas, que no seu tempo com tão vivo estrépido incendiaram o Prata, ainda hoje em volta da sua memória se prolonga o choque das ideias e partidos antagônicos (CORTESÃO 1951, p.13).

Penso que este arrazoado voltava-se exatamente contra uma parte da historiografia argentina que, abrigada na circulação da região historiográfica do Prata, colocava periodicamente a ideia de que o governo do Brasil agira sempre nos moldes imperialistas.

Juntando-se este raciocínio àquele que relaciona as atividades de Cortesão às transformações na corporação diplomática, poderíamos interpretar a sua carta para Lafayette de Carvalho e Souza, diretor do IRB, em 1948, na qual comentava os progressos do seu trabalho (CORTESÃO 1948), como a síntese de um posicionamento articulado nas duas coleções, que compreendia o metajogo da região historiográfica platina e que era colocado em apoio e 
apoiado por uma parte da corporação diplomática que se reunia em torno de um projeto para o IRB.

Esse posicionamento simultaneamente se colocava contra certas correntes da historiografia argentina, mas também da historiografia brasileira, que operavam separadamente no metajogo historiográfico e político da região e com objetivos assemelhados.

Este conceito dominante no Prata, pretende ser a base histórica da política revisionista, em particular dos argentinos, que nunca perderam a chance de reaver o território de Palmas [...] e declaram como um problema em aberto, o do Território dos Sete Povos [...] A futura obra do Instituto [...] será, sem ter o ar expresso, a resposta e o desmentido categórico àquela propaganda nacionalista, revisionista e acintosamente deformadora da história (CORTESÃO 1948).

\section{As origens do revisionismo e a criação da Comissão Brasileira Revisora}

Por outro lado, existiria alguma conexão entre o embate de Cortesão com Rodrigo Octávio, a atuação da corporação diplomática e, o estabelecimento de prescrições estatais sobre a publicação e circulação das obras didáticas de história e de geografia no Brasil?

A Comissão Nacional do Livro Didático (CNLD), constituída em 1938 e consolidada em 1944 é considerada a predecessora do Programa Nacional do Livro Didático (PNLD), e se entende que a CNLD incorporou as atribuições da Comissão Brasileira Revisora dos Textos de Ensino de História e Geografia, reunida no ano de 1936, para atender às prescrições do Convênio firmado entre o Brasil e a Argentina em 10 de outubro de 1933 (OLIVEIRA; FREITAS 2013, p. 8-10).

Contudo, os textos acadêmicos dedicados a avaliar a Comissão Revisora e os seus efeitos têm, de modo geral, apontado sua origem nas iniciativas da Liga das Nações que visavam, então, revisar as obras didáticas com o fim de se eliminar delas os conteúdos chauvinistas que ainda alimentavam o antagonismo entre os membros dessa Liga (LEITE 2010a, 2010b, 2011; CELESTE FILHO 2010; SILVA 2011). Nesta compreensão as iniciativas da Liga, desenroladas inicialmente na Europa, teriam se desdobrado para as Américas e, segundo Ana Paula Silva, no caso específico de Brasil e Argentina, fariam "parte de um projeto que reunia intelectuais e políticos das classes dominantes, ligados à diplomacia, e seus projetos de futuro" (SILVA 2011, p. 270-271). Mesmo assim, alguns destes autores observaram a manutenção de algumas práticas do MRE no que dizia respeito ao seu papel na revisão dos textos didáticos, "não obstante a oscilação política" (LEITE, 2011, p. 87), por exemplo a evocação estrita daquele Convênio de 1933 no auge da Ditadura Militar (CELESTE FILHO 2010, p. 256).

Sem destituir a importância e a influência das iniciativas e das atividades ligadas à Liga das Nações e o argumento da interpenetração dos projetos de poder das elites brasilo-argentinas (SILVA 2015), nossa intenção é demonstrar que a Comissão Revisora de 1936 se integrava na partilha de interesses e tarefas assumida, desde 1838, pelo IHGB e o MRE (PEIXOTO, 2015, p. 48-49), e que a inserção de Jaime Cortesão no MRE possibilitou à corporação diplomática viabilizar sua autonomia em torno do IRB. 
Portanto, não importaria compreender apenas o debate de origem da Comissão, mas também sua solução, na medida em que a inauguração dos instrumentos de intervenção direta nos conteúdos didáticos desencorajava, indiretamente, a produção acadêmica que não atendesse às diretrizes manifestadas pelos governos dos países envolvidos, mas idealizadas por suas instituições e corporações.

Nesse sentido, entendo que a produção e a liderança acadêmica de Cortesão era determinante para o engajamento do IRB na defesa de uma produção histórica e geográfica revisionista inaugurada em 1928, na medida em que por esta se permite incrementar a disseminação de uma visão identitária e espacial que endossava a participação dos diplomatas na criação da Nação. Permite-se afastar as possibilidades de confronto e aproximavam-se as nações do Prata numa articulação a ser desempenhada continuamente pelos diplomatas.

Alguns problemas devem ser apresentados ao leitor para que possamos explicar a relação da Comissão Revisora com os textos de Rodrigo Octávio e como estes podem estar concatenados com o escrito de Cortesão em 1956.

Por um lado, Cortesão se engaja na discussão na década de 1940, mas seu escrito se apresenta ao metajogo de 1950, na medida em que se procurava rever, no Brasil e na Argentina, os conteúdos historiográficos e geográficos já sedimentados desde a Comissão.

No Brasil, os defensores do alinhamento com os Estados Unidos na Guerra Fria o explicavam junto à articulação do posicionamento do Brasil como a potência regional da América do Sul por conta da "aliança não escrita" com os Estados Unidos (PEIXOTO 2011). Na Argentina, o Ministério da Educação buscava a criação de uma comissão para revisar a atuação política de Juan Manuel de Rosas. Seus defensores apontavam que este deveria ser valorizado exatamente pela defesa dos interesses nacionais, pela oposição ao domínio estrangeiro e à dependência econômica e contra as classes econômicas que buscavam seus modelos no exterior (RODRÍGUEZ 2001, p. 58).

Por outro lado, os textos de Rodrigo Octávio se colocam no metajogo de 1930 a partir da oportunidade de endossar o Primer Congreso de Historia Nacional do Uruguai de 1928, e não dos Convênios de 1933 com a Argentina e o Uruguai. Estes dois, mais celebram e regulam uma região historiográfica do que inauguram um concerto, na medida em que o Primer Congreso deriva de uma interação entre as instituições históricas e os historiadores, que remontava ao século XIX. Entendo, assim, que a solução do Primer Congreso em torno do revisionismo se deu em face do contexto geopolítico sul-americano, dos anos 1920, e em razão da organização de um consenso na região historiográfica do Prata.

A criação no Uruguai da Junta de Historia y Numismática Nacional, em 1926, possibilitou a renovação dos contatos entre os intelectuais e as instituições desse país com os seus congêneres brasileiros, na medida em que esta se apresentava paralelamente ao Instituto Historico y Geografico del Uruguai (IHGU), mas colocando-se, enquanto uma instituição, mais dinâmica e capaz de incorporar a nova intelectualidade, ainda que esse caráter renovador e antielitista não se verificasse sempre em suas práticas e que sua existência 
fosse decididamente amparada pelo Estado (ZUBILLAGA 2002, p. 250-251; 2003, p. 182).

No caso da Argentina, somente no final da década de 1930 é que a transformação da Junta de Historia y Numismática Americana na Academia Nacional de la Historia (ANH) se consumaria enquanto um processo de renovação dos estudos históricos premiando a ascensão da Nueva Escola Histórica. Esta, por sua vez, apresentava a proposição de superar a velha tradição monografista e biográfica para reescrever cientificamente a história de seu país e consagrava a posição de seus integrantes numa nova rede institucional de investigação e ensino da História, que controlava as Universidades de Buenos Aires e La Plata (PRADO 2001, p. 17-18).

Por conseguinte, interpreto que o consenso historiográfico regional foi alcançado pela atuação de uma nova instituição, a Junta uruguaia, mais sintonizada com as transformações políticas e historiográficas que seus congêneres platinos. Nesse caso, teria se aproveitado a oportunidade das comemorações da independência do Uruguai, inclusive pelo dissenso em torno da celebração dessa efeméride, para acertar no Primer Congreso o concerto revisionista, que seria chancelado no Brasil em 1931, por iniciativa do representante uruguaio, no Segundo Congresso de História Nacional.

\section{As bases da Comissão brasileira e o metajogo do Prata em 1928}

De que modo os escritos de Rodrigo Octávio se posicionaram no metajogo da região historiográfica platina, e como a produção de Cortesão se articularia com o esforço continuado de certos elementos da corporação diplomática?

As análises acerca da Comissão Revisora de 1936 e dos Convênios de 1933 não consideram a participação original dos uruguaios e se basearam mais no exame dos textos finais da Comissão brasileira - suas Normas e Decretos do que na investigação de suas atividades. Assim, é possível reconstituir boa parte de suas discussões e de seus antecedentes por meio das Atas das suas reuniões e dos documentos preparatórios guardados pelo Arquivo Histórico do Itamaraty (AHI).

A composição mesma da Comissão brasileira já nos diz muita coisa, na medida em que praticamente toda ela era integrada por membros do IHGB e representantes do MRE, sendo que vários deles participavam das duas organizações - é o caso, por exemplo, de José Carlos de Macedo Soares, o presidente da Comissão no início de suas reuniões, quando ocupava o posto de Ministro das Relações Exteriores e, depois, chegaria a ser o presidente do IHGB.

Praticamente toda a discussão se desenrolou a partir das chamadas "bases", elaboradas por Pedro Calmon, as quais, por sua vez, eram inspiradas na sua História da Civilização Brasileira. Ao contrário do que ficaria registrado, a Comissão começaria descortinando a ideia da revisão dos textos de história e geografia a partir da remissão aos países sul-americanos, e somente na segunda reunião mudou-se o foco da revisão para o pan-americanismo.

Sobre essa revisão - e será para esse ponto que migraremos nossa análise - , resguardam-se, principalmente, as origens da Comissão em suas Atas: ela 
devia sua existência aos entendimentos dos diplomatas Hélio Lobo e Freitas Valle em suas passagens pela legação de Montevidéu, quando participaram dos preparativos para o centenário da independência do Uruguai e, em decorrência deste, também do Primer Congreso, quando se propôs a revisão dos textos de história no Uruguai, no Brasil e na Argentina.

Hélio Lobo, colega de Jaime Cortesão na docência do Curso de Aperfeiçoamento de Diplomatas e diretor do IRB, à época do Plano de Estudos, fora também um dos preparadores dos entendimentos preparatórios do Primer Congreso, inclusive, daquele que previa a participação de representantes dos Governos brasileiro e argentino.

O representante do Brasil foi Braz do Amaral, deputado federal, presidente da Comissão de História Diplomática da Câmara dos Deputados e membro do IHGB. Sua participação foi marcada pelo apontamento de que os conflitos no século XIX teriam sido resultantes da herança colonial e, portanto, das desavenças entre Portugal e Espanha, as quais não faziam mais sentido para as nações do século XX. Ora, Braz do Amaral repetiu praticamente todos os argumentos já apresentados no IHGB, exatamente por Rodrigo Octávio e Hélio Lobo, à diferença que o primeiro destacava Gusmão como sendo o idealizador da ultrapassagem da herança colonial, enquanto o segundo colocava a questão mais nos termos geopolíticos visando lembrar a importância da intromissão da Inglaterra no conflito - uma reminiscência importante - para pensarmos o posterior posicionamento de Cortesão.

Tendo ficado à frente da Comissão de História Diplomática, Braz do Amaral defendeu que não fossem publicados os trabalhos ofensivos a quaisquer das nações americanas, e como resultado dessa proposição foram reprovados dois trabalhos e um outro foi encaminhado para modificar - tudo por causa de suas críticas ao imperialismo brasileiro. Seria exatamente pela tensão provocada por essas reprovações que um dos representantes uruguaios, Enrique Rogberg Bálparda, apresentou a proposta, depois aprovada pela Plenária, de que fosse feita a revisão dos livros didáticos de História nos três países.

No Brasil, isto seria transubstanciado por Rodrigo Octávio, na tese Tratado de Paz com as Províncias Unidas do Prata - 1824, a qual foi apresentada ao Segundo Congresso de História Nacional em 1931 junto com o pedido de aprovação da proposição de Bálparda, logrando êxito nas duas proposições.

Penso que as bases desse entendimento em torno da proposta de Enrique Rogberg Bálparda já haviam sido costuradas desde 1926, e depende de considerarmos tanto a ideia da região historiográfica platina quanto a da continuidade dos esforços combinados do IHGB e do MRE.

Em 1926, surgiu a Junta uruguaia, reunindo vários integrantes do Governo e de instituições oficiais, em razão da incapacidade do IHGU em absorver novos membros e se dedicar a atividades mais abrangentes. Entre as suas primeiras atividades, propôs-se a organização de um congresso histórico internacional para a comemoração do centenário da independência e que recebesse os representantes da Inglaterra, Brasil e Argentina, exatamente o Primer Congreso pelo qual trabalhou o diplomata Hélio Lobo, futuro diretor do IRB. A organização da Junta 
foi inspirada nos modelos do IHGB e da Junta argentina; logo após a sua fundação Arturo Scarone, diretor da Biblioteca Nacional do Uruguai, ficou encarregado de estabelecer ligações com o IHGB, missão que desempenhou durante uma viagem oficial ao Rio de Janeiro para entregar à Biblioteca brasileira uma coleção de publicações oferecidas pelo seu Governo como gesto de intercâmbio cultural.

Desse modo, tanto a proposta da instituição quanto a ideia do que deveria ser o futuro evento ficaram bastante claras no discurso pronunciado por Aquiles B. Oribe durante a comemoração do primeiro aniversário da Junta: não seria apenas ensinar a história, mas "depurá-la de todas suas inexatidões", e sua justificativa era a de que a evolução da história fora tão completa que se requeria a sua revisão, pois "pareciam ter sido outros os atores de sua história" (ORIBE 1928, p. 116-118).

\section{Considerações finais}

Em um de seus livros, Ian Buchanan comenta surpreso o fato de que Luce Giard, principal biógrafa de Michel de Certeau, ter informado que não entendia por que Certeau lia e relia O 18 Brumário de Louis Bonaparte. Para Buchanan, era óbvio que ele, assim como Marx, se perguntavam o porquê dos mortos não poderem ser deixados enterrar e por que recorríamos tão prontamente a mitos e fantasmas. Afinal, acalmar os mortos seria a principal tarefa dos historiadores desde Michelet: "encontrar os sentidos discursivos para colocá-los a descansar, mas, fingindo que haviam sido outros os que lhes perturbaram" (BUCHANAN 2000, p. 54).

Contudo, observo que outras informações nos são dadas por Giard: não apenas Certeau lia o 18 Brumário em francês e alemão, mas este texto fora crucial para todos os seus escritos sobre historiografia (GIARD 1998, p. xii), o que também deveria surpreender Buchanan, uma vez que a observação de Marx se dá num texto sobre o político e sobre as representações do político, problemas que não eram o foco dos exames de Certeau.

Provavelmente outros problemas também deveriam estar sendo apresentados a Certeau em sua leitura do 18 Brumário, uma vez que a célebre frase "Deixe os mortos enterrarem seus mortos" se abre no texto de Marx em mais sentidos: "A fim de alcançar seu próprio conteúdo, a revolução do século XIX deve deixar que os mortos enterrem seus mortos" (MARX 1996, p. 34). Penso que aqui Marx trata de apontar que o conteúdo das representações do velho político não servia aos revolucionários do século XIX, os quais deveriam buscar o seu conteúdo, ou seja, em vez de tornar negativa a busca da representação do político na história, Marx apontava um sentido positivo e ativo, ao alinhá-la com os conteúdos condizentes a eles: "A revolução social do século XIX não pode criar sua poesia do passado, mas somente do futuro [...] Lá a frase transcendeu o conteúdo, aqui o conteúdo transcende a frase" (MARX 1996, p. 34).

Mas talvez Buchanan devesse ter reparado que o mais intrigante não fosse pensar o porquê de recorrermos tão facilmente a mitos e fantasmas, mas o problema de que o próprio Marx recorreu a uma frase bíblica que se encaixava relativamente bem nas suas preocupações: "Mas Jesus lhe disse: 'Deixa os mortos enterrarem os seus mortos, porém tu vais e anuncia o Reinado de Deus'" (Lucas 9:50). 
Provavelmente isto não escapou a Certeau, obviamente porque ele era um jesuíta e, afinal, esta é apenas uma das várias passagens do 18 Brumário em que Marx faz das referências religiosas o motor pelo qual o problema da representação foi analisado. Não poderia ser o problema da representação do político que tenha "deliciado" Certeau, como apontou Giard (1998, p. xii), mas, ao mesmo tempo, o incomodado?

Afinal, não se infere por isto a questão mesma da interpretação, tão central nos seus textos, a ponto de se querer destruir os falsos deuses da história? Pois Marx, em vez de tão somente destruir as representações não estaria argumentando em busca de outra representação, aquela que pudesse conduzir os revolucionários à verdade da Revolução? Não foi assim que Marx revelou, numa carta para Friedrich Engels em 1861, a sua admiração por Espártaco, como um real representante do proletariado dos tempos antigos? (MARX 1861).

O problema talvez seja que para Certeau a interpretação e, por extensão, a historiografia, tivesse mais a ver com Freud ou Nietzsche, do que com Marx ou Hegel, e que nesse sentido, ele tivesse que atravessar primeiro pelo cultural, para somente depois alcançar o político, como esclarece Buchanan (2000, p. 57).

Neste ponto, creio que Certeau dialogou e/ou foi influenciado por Pierre Klossowski, assim como também outros pensadores franceses do período: Michel Foucault, Jacques Derrida e Gilles Deleuze. Inclusive Foucault julgava que a melhor obra de filosofia que havia lido era Nietzsche e o Círculo Vicioso, da autoria de Klossowski (SMITH 2012, p. vii; 263-265).

Penso que a contribuição de Klossowski à compreensão da representação por aquela geração foi imensa e esta se deu por meio das definições e discussões de Nietzsche e o Círculo Vicioso, especialmente por conta de conceitos como simulacro, estereótipo, fantasma, prótase e apódase, articulados na reflexão dos problemas colocados por Nietzsche, onde emprestava especial atenção ao emprego do termo "suppôt".

Neste ponto da argumentação, gostaria de fazer notar que Certeau e Klossowski dividiam a mesma experiência religiosa e, por conseguinte, as referências colocadas pela sua intensa preparação teológica, filosófica e espiritual. Enquanto Certeau seguira na Companhia de Jesus, Klossowski deixara o seminário da Ordem de São Domingos e, a despeito dessa decisão, a vivência ali impactou profundamente a sua escrita literária e acadêmica.

"Suppôt" é um termo utilizado na língua francesa do século XVI (segundo Daniel W. Smith, um dos melhores especialistas em Klossowski e Deleuze), e Klossowski o manteve em lugar de qualquer outro termo em Nietzsche $e$ o Círculo Vicioso porque "suppôt" era intraduzível para o francês do século $X X$, já que era apenas substituído imperfeitamente pela palavra "agente" (SMITH 2012, p. xii-xiii).

Originalmente, o termo "suppôt" remete à filosofia escolástica como equivalente ao termo "suppositum", uma substância que se completaria nela mesma e, independente de outras, era capaz de atuar ou sofrer por si mesma. No entanto, se cada "suppositum" era considerado uma substância, o contrário não seria verdadeiro, pois havia o caso de duas substâncias serem 
tão unidas que formariam um único "suppositum", o que, aliás, é o caso do homem, considerado a união de duas substâncias incompletas: a alma e o corpo (HUNTER 1896, p. 149-150).

Prova de que Michel de Certeau não desconhecia o termo "suppôt" é a de que, pelo menos uma vez, este foi utilizado na edição francesa de $A$ escrita da História, muito embora a tradução brasileira tenha preferido substituir "suppôt" pelo termo "agente" (CERTEAU 1975, p. 273; 2002, p. 264). No entanto, essa diferença em relação a Klossowski nos aponta um rastro que levaremos em consideração no curso deste raciocínio, pois o termo "suppôt" não poderia ter para Certeau a mesma importância que Klossowski lhe atribuía, pois era o "outro" que ele procurava interpretar e não a ideia de uma ligação que percorreria a representação e perfaria sua economia.

Num raciocínio que guarda semelhanças com o arrazoado de Certeau em torno da invenção do quotidiano, Klossowski pressupõe nas ideias do fantasma e do simulacro, não apenas um estado obsessional, mas também sua reprodução intencional a partir de um repertório, "os códigos de sinais do cotidiano" [le code des signes quotidiens], onde a lucidez não se oporia à ideia de delírio.

Nessa economia, o fantasma seria uma produção dos impulsos e deixaria de ser comunicável em si mesmo, daí a necessidade do simulacro. Como a célebre tirada de Marx no 18 Brumário, Klossowski também lembraria que o simulacro toma a forma de mito ou paródia. No sentido da sugestão de Marx acerca de Espártaco, para Klossowski a produção do simulacro não seria negativa ou positiva, mas parte de uma economia crucial: o movimento criador de uma linguagem que não seria traduzida estritamente ou intercambiada: Klossowski apontaria mesmo que "a impotência para inventar simulacros é, portanto, apenas um sintoma de degenerescência" - situação que não desafia apenas a invenção dos simulacros, mas a sua interpretação (KLOSSOWSKI, 2000, p. 155).

Interessa-nos aqui mostrar que esta é parte de uma solução possível de ser articulada pelos contributos acessíveis a Certeau e que pode ser alargada de modo a aventarmos que Cortesão buscava em Gusmão justamente o mito, utilizando a representação do político em si, enquanto uma forma de interpretar a realidade. Resedimentar Gusmão não era apenas produzir um simulacro dentre tantos outros, mas constituir uma ligação com aquilo que tanto prezava - a Liberdade - por meio do repertório que operava e através das oportunidades que se lhe apresentaram.

Isto fica ainda mais claro quando Cortesão se afirma neo-hegeliano e crociano - no juízo acerca de Pedro de Angelis - o mito de Gusmão não servia para acalmar os mortos:

Somos dos que pensam que no juízo sobre os homens não pode separarse inteiramente o intelectual do ser moral [...] Ao historiador, e muito mais se partilhar, como nós, o conceito neo-hegeliano de Croce sobre a história, não é lícito oferecer uma homenagem incondicional a essa espécie de homens, por mais serviços que tenham prestado à cultura universal. Do contrário, poderá, a justo título, concluir-se que ele aceita e desculpa, por simples amor de erudição, as traições à missão humana e divina do espírito, que é afirmar e defender o espírito criador e a sua expressão livre e isenta (CORTESÃO 1951, p. 52-53). 


\section{Referências bibliográficas}

\section{Documentação primária}

CORTESÃO, Jaime. [Correspondência] 29 dez. 1948. Rio de Janeiro [para] Carta a Lafayette de Carvalho e Souza. Biblioteca Nacional, Seção de manuscritos, 30.1.001 n. 15.

MARX, Karl. Marx to Engels in Manchester' [London, 27 feb. 1861]. Marx-

Engels Correspondence. Marx \& Engels Internet Archive: Letters. Disponível em: <http://marxists.anu.edu.au/archive/marx/works/1861/ letters/61_02_27.htm>. Acesso em: 01 jan. 2016.

MRE. Ata da Comissão Brasileira Revisora dos Textos de Ensino de História e Geografia, constituída em virtude do Convênio com a República Argentina, assinado no Rio de Janeiro a 10 de outubro de 1935. AHI, 135113.

. Contrato entre Jaime Cortesão e o Ministério das Relações Exteriores em 12 de fevereiro de 1942. Memorandos e Relatórios de 1946a. AHI. 1365 13-16. Manuscrito.

- Memorando de Hildebrando Accioly, Diretor do IRB, para o Ministro das Relações Exteriores João Neves da Fontoura em 4 de fevereiro de 1946. Memorandos e Relatórios de 1946b. AHI, 1365 13-16. Manuscrito.

- Memória de Lauro Escorel Rodrigues de Morais sobre a criação do Instituto Rio Branco. 1946. Memorandos e Relatórios de 1946c. AHI, 136 5 13-16. Manuscrito.

- Memorando de Hildebrando Accioly, Diretor do IRB, para o Ministro das Relações Exteriores João Neves da Fontoura. 5 de junho de 1946. Memorandos e Relatórios de 1946d. AHI, 1365 13-16. Manuscrito.

. Memorando de Hélio Lobo, Diretor do IRB, para o Ministro das Relações Exteriores, João Neves da Fontoura em 25 de março de 1947. Memorandos e Relatórios de 1947a. AHI, 1365 13-16. Manuscrito.

- Plano de Pesquisa no Brasil. Memorando de Hélio Lobo, Diretor do IRB, para o Ministro das Relações Exteriores em 23 de abril de 1947. Memorandos e Relatórios de 1947b. AHI, 1365 13-16. Manuscrito.

- Memorando de Astréa Dutra dos Santos, pesquisadora de História do IRB para o Secretário Geral em 24 de dezembro de 1947c. AHI, 1365 13-16. Manuscrito.

- Memorando de Guimarães Rosa, Chefe da Secretaria do IRB para Lafayette de Carvalho e Silva, Diretor do IRB em 28 de maio de 1947. Memorandos e Relatórios de 1947d. AHI, 1365 13-16. Manuscrito. 


\section{Obras de apoio}

BUCHANAN, Ian. Michel de Certeau: Cultural Theorist. London: SAGE Publications, 2000.

CELESTE FILHO, Macioniro. A proposta da Organização dos Estados Americanos para a censura de livros brasileiros de História no auge da ditadura militar. In: MARTINS, Maria A. S. R. (Org.). Educação, mídia e cognição. Bauru: Canal 6, 2010, p. 237-260.

CERTEAU, Michel de. L'écriture de I'histoire. Paris: Gallimard, 1975.

A Escrita da História. Rio de Janeiro: Forense Universitária, 2002.

CORTESÃO, Jaime. Introdução. Manuscritos da Coleção De Angelis: Jesuítas e Bandeirantes no Guairá (1594-1640). Rio de Janeiro: Biblioteca Nacional, Divisão de Obras Raras, 1951. v. 1.

Introdução. Alexandre de Gusmão e o Tratado de Madri. Parte I, Tomo I, Rio de Janeiro: Imprensa Nacional. 1952.

. Introdução. Alexandre de Gusmão e o Tratado de Madri. Parte I, Tomo II, Rio de Janeiro: Imprensa Nacional. 1956.

GIARD, Luce. How tomorrow is being born. In: CERTEAU, Michel; GIARD, Luce.

The capture of speech and other political writings. Minneapolis: University of Minnesota Press, 1998.

HUNTER, Sylvester Joseph. Of The Society of Jesus. Manuals of Catholic Theology, Outlines of Dogmatic Theology. New York, Cincinnati, Chicago: Zigkr Brothers, Printers to the Holy Apostolic, 1896. v. II.

JORGE, Arthur G. A. Alexandre de Gusmão: o avô dos diplomatas brasileiros (1695-1753). Ensaios de História e Crítica. Rio de Janeiro: Imprensa Nacional, 1916, p. 1-50.

KLOSSOWSKI, Pierre. Nietzsche e o círculo vicioso. Rio de Janeiro: Pazulin, 2000.

LEITE, Juçara L. Pensando a paz entre as guerras: o lugar do ensino de História nas Relações Exteriores. Antíteses, v. 3, p. 677-699, 2010a.

Professores e políticos em nome da paz: interesses internacionais por uma história ensinada. Saeculum, v. 22, p. 103-113, 2010 b.

- Revisando livros didáticos de História: ação da diplomacia cultural em nome da paz. Tempo e Argumento, v. 3, p. 77-99, 2011.

MARX, Karl; CARVER, Terrell. Marx: Later political writings. Cambridge: Cambridge University Press, 1996.

OCTÁVIO, Rodrigo, Alexandre de Gusmão e o Monroísmo. Revista do IHGB, v. 175, p. 5-69, 1941.

OLIVEIRA, Margarida M. D. ; FREITAS, Itamar. Historiografia didática e prescrições estatais sobre conteúdos históricos em nível nacional (1938-2012).

Territórios e Fronteiras, v. 6, p. 6-24, 2013. 
ORIBE, Aquiles B. Discurso del señor Aquiles B. Oribe. Junta de História Nacional. Montevideo: Imp. El Siglo Ilustrado, 1928. v. III.

PEIXOTO, Renato Amado. Depois aconteça o que acontecer: por uma rediscussão do Caso Panther e da política externa de Rio Branco. Revista Brasileira de Política Internacional, v. 54, p. 44-66, 2011 a.

. Enformando a Nação. Cartografias Imaginárias: estudos sobre a construção do espaço nacional brasileiro e a relação História \& Espaço. Natal: EDUFRN, 2011b.

- A flecha e o alvo: as origens, as transformações e a função do curso de História da Cartografia lecionado por Jaime Cortesão no Ministério das Relações Exteriores. Antíteses, v. 7, p. 184-209, 2014.

. O modelo e o retrato: Jaime Cortesão, a História da Formação Territorial do Brasil e sua articulação com a História da Cartografia brasileira. História da Historiografia, n. 19, p. 46-65, 2015.

PRADO, Gustavo H. La historiografia argentina del siglo XIX en la mirada de Rómulo Carbia y Ricardo Levene: problemas y circunstancias de la construcción de una tradición. 1907-1948. In: PAGANO, Nora; RODRÍGUEZ, Martha. La Historiogafia Rioplatense en la Posguerra. Buenos Aires: La Colmena, 2001, p. 9-36.

RODRÍGUEZ, Martha. Cultura y educación bajo el primer peronismo: el derrotero academico institucional de Ricardo Levene. In: PAGANO, Nora; RODRÍGUEZ, Martha. La Historiogafia Rioplatense en la Posguerra. Buenos Aires: La Colmena, 2001, p. 39-66.

SMITH, Daniel W. Translator's Preface In: KLOSSOWSKI, Pierre. Nietzsche and the Vicious Circle. Chicago: The University of Chicago Press, 1997, p. vii-xiii.

SILVA, Ana Paula B. R. Diálogos sobre a Escrita da História: Brasil e Argentina (1910-1940). Brasília: Fundação Alexandre de Gusmão, 2011.

História e integração regional: intelectuais, convênios e livros no Brasil e na Argentina nas primeiras décadas do século XX. História da Historiografia, n. 18, p. 231-247, 2015.

ZUBILLAGA, Carlos. Historia e historiadores en el Uruguay del siglo XX: Entre la Profesión y la Militancia. Montevideo: Librería de la Facultad de Humanidades y Ciencias de la Educación/Universidad de la República, 2002.

. Comunidades historiográficas y renovación disciplinaria en Uruguay. 180. Revista Complutense de Historia de América. v. 29, p. 179-191, 2003. 